\title{
Burkholderia pseudomallei: A CASE REPORT OF A HUMAN INFECTION IN CEARÁ, BRAZIL
}

Iracema Sampaio MIRALleS(1), Maria do Carmo Alves MACIEL(1), Maria Rozzelê Ferreira ANGELO(1), Mirna Moura GONDINI(1), Luiza Helena Feitosa FrOTA(1), Cristhiane Moura Falavina dos REIS(2) \& Ernesto HOFER(2)

\begin{abstract}
SUMMARY
Burkholderia pseudomallei has rarely been isolated from environmental and clinical specimens in South America, particularly, in Brazil. This report describes a case of melioidosis with fulminant sepsis in a 10 year old boy, from rural area, in Tejuçuoca, State of Ceará, Brazil. Blood samples were positive and, through the analysis of results from biochemical tests and of drugs susceptibility profile, identified this gram-negative bacillus as B. pseudomallei. The contamination source remains obscure in this case, as soil and water tanks samples submitted to microbiological analyses did not indicate the presence of B. pseudomallei.
\end{abstract}

KEYWORDS: Burkholderia pseudomallei; Melioidosis; Ceará; Brazil.

\section{INTRODUCTION}

In Burma, 1912, Whitmore and Karishnaswami described a human disease with the same characteristics of glanders (farcy), one of the most ancient zoonosis mentioned by Aristotle and Hippocrates, respectively, on $2^{\text {nd }}$ and $4^{\text {th }}$ centuries, BC (VERNON, 1989) ${ }^{20}$. This bacterium was isolated by Whitmore (1913) and named Bacillus pseudomallei. The disease was called melioidosis (STANTON \& FLETCHER, 1925) ${ }^{17}$, from the Greek melis (malign) and ë̈los (similar). The Whitmore bacterium was, therefore, included in several genus: Pfeifferella, Malleomyces, Loefflerella, Whitmorella, Flavobacterium, Pseudomonas, and in the new genus Burkholderia with other species known to cause human and animal infections: B. mallei, B. cepacia, B. pickettii (Ralstonia pickettii, new name), and B. gladioli $^{22}$.

Burkholderia pseudomallei is a telluric microorganism. It survives on tropical wet soil, within stagnated water, such as rice paddies, and may spread over several animal species, particularly rodents ${ }^{18}$. The human disease is prevalent on southwestern Asia (Vietnam, Cambodia, Thailand, and Malaysia); less prevalent on northern Australia, India and China, and it rarely occurs on American or African tropical areas ${ }^{12}$.

From the epidemiological point of view, several animal species may function as reservoirs of the microorganism or may be susceptible to the disease ${ }^{9}$.

Human transmission occurs by inhalation of infected dust or water particles, ingestion of or contact of skin lesions with soil or water containing the organism. A classical description of this infection was the inhalation of dust or water particles on the landing areas of helicopters during the Vietnam war ${ }^{10}$.

Clinically, infections may appear in its acute form, spreading fulminant sepsis; subclinically, it may last for a long period ${ }^{13}$. The most common manifestations are bacteriemia; pneumonitis; pulmonary, splenic, hepatic, and cutaneous abscesses and, more rarely, osteomyellitis, lymphadenitis and a chronic granulomatous disease, in individuals that present a genetical deficiency of the NADPH oxidase system of phagocytes $^{5}$. It is worthy of note that symptomatic forms in men and animals occur, mostly, in prevalent areas at rainy seasons ${ }^{1}$.

\section{CASE DESCRIPTION}

By the end of February, 2003 four cases of sepsis syndrome in adolescents of the same family, aging 10-15 years old, were notified to the State Health Secretary from the State of Ceará. They lived in an abandoned house at the rural area of Tejuçuoca municipality, in the Center-North area of the state.

The previous diagnosis was hemorrhagic dengue, hantavirus, plague, leptospirosis, and salmonellosis (since the presence of rodents is common in this area). However, the etiologic finding came from the blood culture of a 10 year old male patient, whose first symptoms appeared on March 1st, 2003: fever, headache, cough, and pustules on limbs. The patient died on March 7, 2003 with fulminant sepsis, as occurred in the two previous cases. Both blood cultures (Bactec-Becton, Dickinson, US) obtained on March 4, 2003 were sent and analyzed by the Public Health Central Laboratory of State (Lacen/CE).

(1) Laboratório Central de Saúde Pública, Secretaria de Estado da Saúde do Ceará, Fortaleza, Ceará, Brasil.

(2) Laboratório de Zoonoses Bacterianas, Instituto Oswaldo Cruz/FIOCRUZ, Rio de Janeiro, RJ, Brasil.

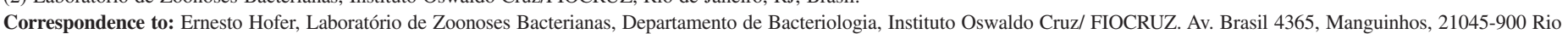
de Janeiro, RJ, Brasil. Phone +55-21-25984277. E-mail: hofer@uninet.com.br 
Bacterial growth was visible after $24 \mathrm{~h}$ of incubation at $37^{\circ} \mathrm{C}$ and bacterioscopy, by Gram method, showed the presence of Gram-negative bacilli, isolated immediately by plated onto a selective MacConKey agar and on nutrient agar with 5\% of defibrinated sheep blood. Three colonies developed in media, red in MacConkey agar and non hemolytic in blood agar were subcultured in presumptive media (Pessoa \& Rugai and Kligler agar), which behavior after incubation was compatible to a Gram negative non fermentative bacteria. Considering an adaptation of a CDC scheme (Hofer, E. Gram negative non fermentative bacteria, 1985 - not published), oxidase test were made as preliminary analyses, such as, action on glucose in O-F medium, motility on semisolid agar plate, besides considering the previous growth on MacConkey agar. All isolates were oxidase positive, motile and oxidizing glucose, allowed classification as belonging to a group, lately represented by Burkholderia genus members, yet more intense due to fluid medium growing at $42{ }^{\circ} \mathrm{C}$. In addition, isolate was identified by automated process (Vitek) which confirmed the genus and recognized the species (81.83\% probability), matching posterior observations accomplished in Laboratório de Zoonoses Bacterianas, Instituto Oswaldo Cruz/Fiocruz/RJ, which, in 10/ 3/2003, received the strain n: 649 from Lacen/CE.

Accomplished analysis indicated to be Gram negative bacilli, arranged singly or in palisade (Gram method) and use of Wayson stain revealed bipolar staining. Taking into account the growing process on nutrient agar with $3 \%$ of glycerol, either the colonies as the sowing in stria showed a profuse growth with dull, wrinkled, corrugated surface after $96 \mathrm{~h}$ at $37^{\circ} \mathrm{C}$; in the case of plate semisolid agar, the bacteria was motile at environmental temperature and at $37{ }^{\circ} \mathrm{C}$, demonstrated a characteristic wrinkling with umbonated centers and radiating ridges after 4 days at $37^{\circ} \mathrm{C}$ (Figs. 1-3).

The conclusive phenotypic characterization of the strain 649 at the genus and species level was performed as described by YABUUCHI et al. (1992) and BRETT et al. (1998). The reactions are summarized in Table 1.

Antibiotic susceptibility testing was performed followed by disk diffusion test, according to the National Committee for Clinical Laboratory Standards (NCCLS) guidelines ${ }^{15}$ and by means of the Vitek - GNS 650 (bioMérieux Vitek, US) automated antimicrobial susceptibility system. Results were interpreted according to the guidelines of NCCLS (Table 1).

Investigations were conducted to determine the source of this child's contamination. Soil samples collected near and inside the house, as well as water tank and animal feces (caprine) were submitted to microbiological examinations. However, cultures on MacConkey agar and nutrient agar with $3 \%$ of glycerol did not revealed the presence of $B$. pseudomallei.

As for autopsy findings, it should be mentioned bronchopneumonia and multiple abscesses in lungs and liver.

Based on clinical presentation and autopsy reports, it is admissible that the patient developed the acute form of melioidosis, though the chronical situation with fulminant intercurrence of sepsis should not be denied. Besides, some authors ${ }^{4,16}$ have referred that, on sepsis melioidosis, patients initially presented a history of fever (average interval of six
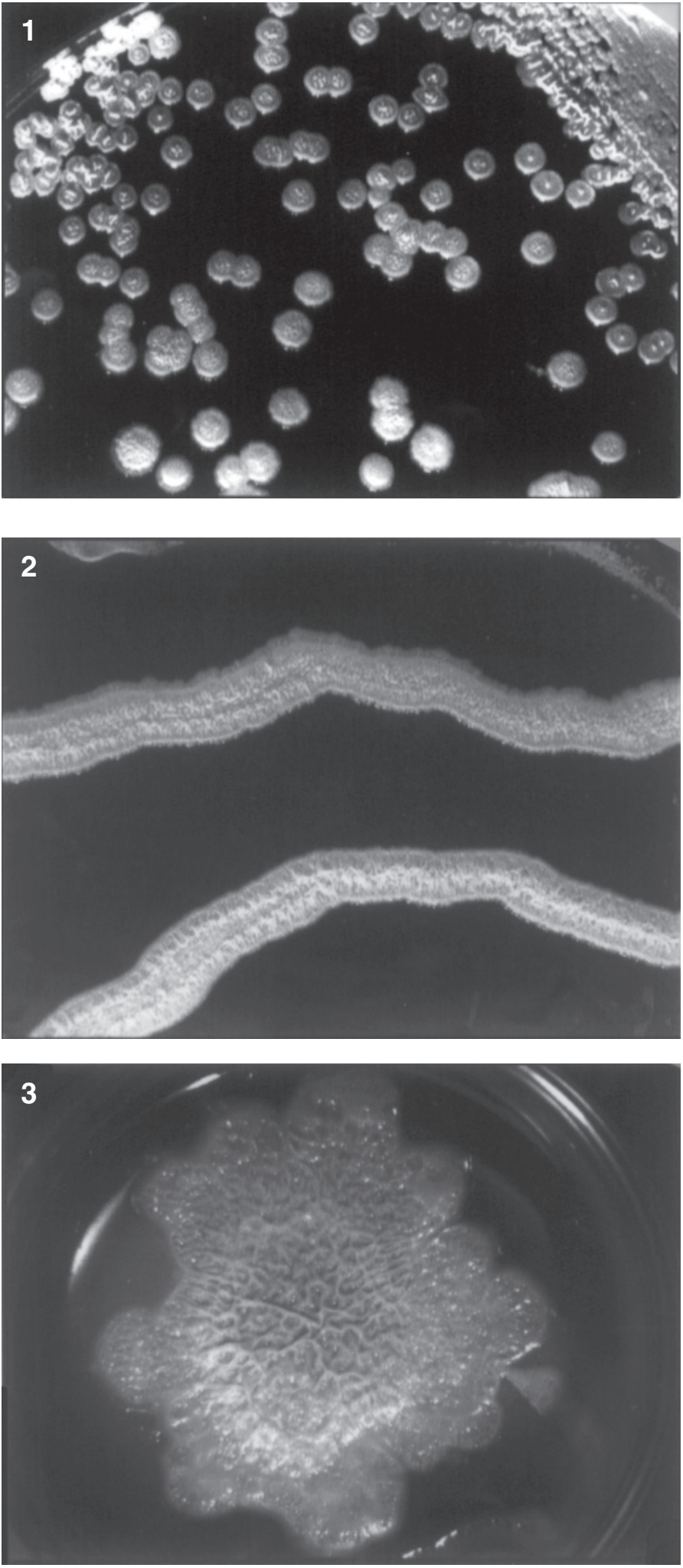

Fig. 1-3 - (1) Growth of colonies (rugose forms) on glycerol agar streak plate after 4 days at $37^{\circ} \mathrm{C}$. (Original magnification). (2) Peculiar appearance of the growth on glycerol agar, 3 days at $37^{\circ} \mathrm{C}$. (3) Wrinkled configuration of growing on soft agar plate, after 4 days at $37^{\circ} \mathrm{C}$. 
Table 1

Phenotypic characteristics of the strain No. 649 (B. pseudomallei)

\begin{tabular}{lcll}
\hline Test & Result & Test & Result \\
\hline Motility & + & $\mathrm{H}_{2} \mathrm{~S}$ (Kligler agar) & - \\
Catalase & + & Arginine dihydrolase & + \\
Oxidase & + & Hydrolysis: & - \\
Growth on: & & Urea & + \\
MacConkey Agar $-37{ }^{\circ} \mathrm{C}$ & + & Gelatin & - \\
Nutrient broth $-42{ }^{\circ} \mathrm{C}$ & + & Esculin & \\
Citrate (Simmons) & + & O-F medium - Oxidation of: \\
& & Glucose & + \\
Nitrate reduction & + & Lactose & - \\
Gas from nitrate & + & Arabinose & - \\
Indole & - &
\end{tabular}

+: Positive; -: Negative.

Table 2

Antimicrobial susceptibility of $B$. pseudomallei strain No. 649

\begin{tabular}{lcc}
\hline Antimicrobial agents & MIC $(\mu \mathrm{g} / \mathrm{ml})$ & Disk \\
\hline Amikacin & $>32$ & $\mathrm{R}$ \\
Ampicillin & 128 & $\mathrm{R}$ \\
Ampicillin/Sulbactam & $>16 / 8$ & - \\
Cefazolin & $>16$ & - \\
Ceftazidime & $>16$ & $\mathrm{~S}$ \\
Ceftriazone & $>32$ & $\mathrm{~S}$ \\
Cephalotin & $>64$ & $\mathrm{R}$ \\
Ciprofloxacin & $>2$ & $\mathrm{R}$ \\
Gentamicin & $>8$ & $\mathrm{R}$ \\
Lomefloxacin & $>4$ & - \\
Nitrofurantoin & $>64$ & - \\
Piperacillin & $>64$ & - \\
Tetracycline & 4 & $\mathrm{~S}$ \\
Trimethoprim/Sulpha & $2 / 38$ & $\mathrm{~S}$ \\
\hline
\end{tabular}

$\mathrm{S}$ - susceptible; $\mathrm{R}$ - resistant

days and, sometimes, months) without evidence of focal infection; but, soon after hospitalization, they developed hypotension with clear signs of organic dysfunctions and with a fast evolution to death. In this sense, it is interesting to emphasize that on bacteremias presenting $>50 \mathrm{ufc} / \mathrm{ml}$ there was a meaningful association between hypotension and posthospitalization, with high lethality rate ${ }^{21}$. On the other hand, in sepsis, due to Enterobacteriaceae members such relation was considered inconsistent ${ }^{6}$.

If it is considered the epidemiologic view, though it is not quite clear, it is possible to suspect of a hydric carrier, during children's play in the water accumulated into the barrier after the rainy period, as well as of a telluric carrier, through contact or inhalation of soil particles. From an analytical point of view, any hypothesis had laboratorial support, as for the absence of Whitmore bacillus from all environmental samples analyzed. It is important to emphasize that, during routine researches on water and soil along different world areas, specifically in the melioidosis sites located in tropical zones within $20^{\circ}$ north and south latitude ${ }^{7}$, the success of isolating B. pseudomallei is quite variable ${ }^{9}$. Still, these authors mention the microorganism detection at soil samples collected from regions of Bahia, Brazil and, also, from Peru and Haiti.

The isolation and characterization of Whitmore bacillus in human and animal cases on Americas are restricted to caprine, swine and ovine occurrences in Aruba $^{19}$, to a human case in Equador ${ }^{2}$, and to a disease survey in the US, where references to cases in Puerto Rico, Martinique, and Guadalupe ${ }^{5}$ were also included. In Brazil, there is no register of animal and human melioidosis occurrence, though a similar species, Burkholderia mallei, was described in equines ${ }^{11,14}$, as well as in clinical materials from hospitalized patients in Fortaleza, Ceará ${ }^{8}$.

Another aspect often referred in literature is the difficulty of establishing a precise laboratorial diagnosis within non endemic or enzootic melioidosis areas. The problem may be reduced by means of identifying commercialized processes, such as, API NFT system, or of automated processes ${ }^{5}$. When any of these resources are available, it is possible to consider morphological characteristics of colonies, associated to classic microbiologic methodology, which are able to present a sure result, counting on a limited number of proofs that enables, initially, to define the species, differing it from other similar ones, as in the case of B. thailandensis, that does not attack oxidatively l-arabinose in O-F medium ${ }^{3}$.

Another probable species indicative is the antimicrobial susceptibility profile, considering sensibility to tetracycline, sulfamethoxazoletrimethoprim, ceftazidime and ceftriaxone, and resistance to ampicillin, cephalosporins ( $1^{\text {st }}$ and $2^{\text {nd }}$ generations), ciprofloxacin and to aminoglycosides. In general, the Brazilian strain presented a similar profile to those of other world regions ${ }^{5}$, with slightly different aspects, such as in the case of ceftazidime and ceftriaxone, which presented discrepant MIC in comparison to impregnated disk results.

Data here reported represent the registry of an autochthonous case of human infection by Burkholderia pseudomallei, an extraordinary 
occurrence for our research environment, which definition was possible solely due to the laboratorial trials done.

\section{RESUMO}

\section{Burkholderia pseudomallei: infecção humana no Ceará, Brasil}

O isolamento de Burkholderia pseudomallei, de meio ambiente e de espécimes clínicos, foi raramente registrado na América do Sul, particularmente no Brasil. Este relato descreve o caso de melioidose em um paciente de 10 anos de idade, de área rural do estado do Ceará (Tejuçuoca). As hemoculturas foram positivas e as análises dos testes bioquímicos e de susceptibilidade aos antimicrobianos do isolado foram indicativos para a identificação de B. pseudomallei. A fonte de contaminação foi obscura, uma vez que as análises microbiológicas de solo e água no tanque foram negativas.

\section{ACKNOWLEDGEMENTS}

Field work was possible due to the collaboration and support of many colleagues at the Secretaria de Estado da Saúde do Ceará, especially Dr Liana Perdigão Mello, director of Laboratório Central de Saúde Pública; Prof Cristina Barroso Hofer for critical reading of the manuscript and Mr Wagner Thadeu Cardoso Esteves for technical assistance.

\section{REFERENCES}

1. ASHDOWN, L.R.; DUFFY, V.A. \& DOUGLAS, R.A. - Melioidosis. Med. J. Aust., 1: 314-316, 1980.

2. BIEGELEISEN Jr., J.Z.; MOSQUERA, R.M. \& CHERRY, W.B. - A case of human melioidosis: clinical, epidemiological and laboratory findings. J. trop. Med. Hyg., 13: 89-99, 1964.

3. BRETT, P.J.; DeSHAZER, D. \& WOODS, D.E. - Burkholderia thailandensis sp. nov a Burkholderia pseudomallei like species. Int. J. system. Bact., 48: 317-320, 1998.

4. CHAOWAGUL, W.; WHITE, N.J.; DANCE, D.A.B. et al. - Melioidosis: a major cause of community-acquired septicemia in northeastern Thailand. J. infect. Dis., 159: 890-899, 1989

5. DOMAN, S.E.; GILL, V.J.; GALLIN, J.I. \& HOLLAND, S.M. - Burkholderia pseudomallei infection in a Puerto Rican patient with chronic granulomatous disease: case report and review of occurrences in the Americas. Clin. infect. Dis., 26: 889$894,1998$.

6. DuPONT, H.L. \& SPINK, W.W. - Infections due to gram-negative organisms: an analysis of 860 patients with bacteremia at the University of Minnesota Medical Centre, 1958 - 1966. Medicine (Baltimore), 48: 307-332, 1969.

7. FOURNIER, J. - Épidémiologie de la mélioïdose. Bull. Inst. Pasteur, 69: 385-399, 1971.
8. FROTA, C.C. \& MOREIRA, J.L.B. - Frequency of nonfermentative Gram-negative bacilli isolated from clinical materials of patients at Universidade Federal do Ceará Hospital Complex - Brazil. Rev. Microbiol. (S. Paulo), 29: 179-182, 1998.

9. GALIMAND, M. \& DODIN, A. - Le point sur la mélioïdose dans le monde. Bull. Soc. Path. éxot., 75: 375-383, 1982.

10. HOWE, C.; SAMPATH, A. \& SPOTNITZ, M. - The pseudomallei group: a review. J. infect. Dis., 124: 598-606, 1971.

11. LANGENEGGER, J.; DÖBEREINER, J. \& LIMA, A.C. - Foco de mormo (Malleus) na região de Campos, estado do Rio de Janeiro. Arq. Inst. Biol. Animal (Rio de J.), 3: 91-108, 1960.

12. LEELARASAMEE, A. \& BOVORNKITTI, S. - Melioidosis: review and update. Rev. infect. Dis., 11: 413-425, 1989.

13. MAYS, E.E. \& RICKETTS, E.A. - Melioidosis: recrudescence associated with bronchogenic carcinoma twenty-six years following initial geographic exposure. Chest, 68: 261-263, 1975.

14. MOTA, R.A.; BRITO, M.F.: CASTRO, F.J.C. \& MASSA, M. - Mormo em equiídeos nos estados de Pernambuco e Alagoas. Pesq. vet. bras., 20: 155-159, 2000.

15. NATIONAL COMMITTEE FOR CLINICAL LABORATORY STANDARDS (NCCLS) - Performance standards for antimicrobial disk susceptibility test. 8. ed. Wayne, 2003. (Approved standard M2-A8).

16. PUTHUCHEARY, S.D.; PARASAKTHI, N. \& LEE, M.K. - Septicaemic melioidosis: a review of 50 cases from Malaysia. Trans. roy. Soc. trop. Med. Hyg., 86: 683-685, 1992.

17. STANTON, A.T. \& FLETCHER, W. - Melioidosis, a disease of rodents communicable to man. Lancet, i: 10-13, 1925.

18. STRAUSS, J.M.; GROVES, M.G.; MARIAPPAN, M. \& ELLISON, D.W. - Melioidosis in Malaysia. II. Distribution of Pseudomonas pseudomallei in soil and surface water. Amer. J. trop. Med. Hyg., 18: 698-702, 1969.

19. SUTMOLLER, P.; KRANEVELD, F.C. \& SCHAAF, A. van der - Melioidosis (Pseudomaleus) in sheep, goats, and pigs on Aruba (Netherlands Antilles). J. Amer. vet. Med. Ass., 130: 415-417, 1957.

20. VERNON, M. - Pseudomonadaceae. In: LE MINOR, L. \& VERNON, M., ed. Bacteriologie médicale. 2. ed. Paris, Flammarion, 1989. p. 555-598.

21. WALSH, A.L.; SMITH, M.D.; WUTHIEKANUN, V. et al. - Prognostic significance of quantitative bacteremia in septicemic melioidosis. Clin. infect. Dis., 21: 1498-1500, 1995.

22. YABUUCHI, E.; KOSAKO, Y.; OYAIZU, H. et al. - Proposal of Burkholderia gen. nov. and tranfer of seven species of the Pseudomonas homology group II to the new genus, with the species Burkholderia cepacia (Palleroni and Holmes 1981) comb. nov. Microbiol. Immunol., 36: 1251-1275, 1992.

Received: 8 August 2003

Accepted: 19 November 2003 